\title{
Prevailing effectiveness of the 2009 influenza A(H1N1) pdm09 vaccine during the 2010/11 season in Sweden
}

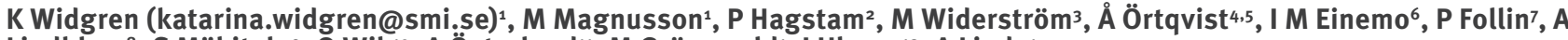 \\ Lindblom $^{8}$, S Mäkitalo9 $^{9}$ O Wik ${ }^{10}$, A Österlund ${ }^{11}, M$ Grünewald ${ }^{1}, I_{\text {I }}$ Unoo ${ }^{12}$, A Linde $^{1}$ \\ 1. Department of Analysis and Prevention, Swedish Institute for Communicable Disease Control, Solna, Sweden \\ 2. Department of Communicable Disease Control and Prevention, Skåne County, Malmö, Sweden \\ 3. Department of Communicable Disease Control and Prevention Jämtland County, Östersund, Sweden \\ 4. Department of Communicable Disease Control and Prevention, Stockholm County, Stockholm, Sweden \\ 5. Department of Medicine, Unit of Infectious Diseases, Karolinska Institute, Solna, Sweden \\ 6. Department of Communicable Disease Control and Prevention, Jönköping Count, Jönköping, Sweden \\ 7. Department of Communicable Disease Control and Prevention, Västra Götaland County, Gothenburg, Sweden \\ 8. Department of Communicable Disease Control and Prevention, Dalarna County, Falun, Sverige \\ 9. Department of Communicable Disease Control and Prevention, Gävleborg County, Gävle, Sweden \\ 10. Department of Communicable Disease Control and Prevention, Värmland County, Karlstad, Sweden \\ 11. Department of Communicable Disease Control and Prevention, Norrbotten County, Luleå, Sweden \\ 12. Department of Diagnostics and Vaccinology, Swedish Institute for Communicable Disease Control, Solna, Sweden
}

Sixty per cent of the Swedish population received the monovalent ASo3-adjuvanted pandemic influenza vaccine in the autumn of 2009. We assessed the age-specific effectiveness of this pandemic vaccine against hospitalisation with laboratory-confirmed influenza $A\left(H_{1} N_{1}\right)$ pdmog during the season 2010/11, in the age group from six months to 64 years in Sweden. The screening method was applied to available surveillance data. Our results suggest a prevailing effectiveness of $72 \%$ ( $95 \%$ confidence interval (Cl): $63-80 \%$ ) with the highest effectiveness among children, six months to nine years-old ( $92 \%, 95 \% \mathrm{Cl}: 80-97 \%)$. However, there were limitations in data quality and study design due to the lack of systematic recording of administered vaccinations, which underline the importance of preparing for an evaluation when planning for large public health actions. Despite these limitations, we believe the results reflect true, high prevailing vaccine effectiveness. Indeed, there were fewer deaths caused by influenza and the impact of influenza on intensive care units was less severe during the 2010/11 season in Sweden than in countries with lower pandemic vaccination coverage. The association between the pandemic vaccine and narcolepsy has increased the importance of assessing the risks and benefits of the vaccination; studies on the effectiveness and the duration of protection are needed for this.

\section{Background}

In the pandemic situation of 2009, Sweden chose to conduct a mass vaccination campaign using the Pandemrix vaccine, a monovalent vaccine containing an influenza $\mathrm{A} / \mathrm{California/7/2009}\left(\mathrm{H}_{1} \mathrm{~N} 1\right)$ v-like strain, adjuvanted with $\mathrm{ASO}_{3}$ (squalene, DL-alpha-tokoferol and polysorbate 80 ). This was the only pandemic vaccine available at the time in Sweden. The whole population was offered the vaccination free of charge. Within a period of 10 weeks from October to December $2009,60 \%$ of the population received at least one dose of the pandemic influenza vaccine. Thus, Sweden had the highest national pandemic vaccination coverage in the European Union [1]. During seasonal influenza years, only non-adjuvanted trivalent inactivated influenza vaccines have been used in the country. Adjuvanted vaccines are considered to elicit a stronger, longer-lasting and broader immune response $[2,3]$ and adjuvants make it possible to save time by producing larger quantities of vaccine with a smaller amount of antigen. Therefore, adjuvanted vaccines had been recommended by the World Health Organization in preparation for a pandemic of influenza $\mathrm{A}\left(\mathrm{H}_{5} \mathrm{~N}_{1}\right)$ in 2005 [4] and were also supported for influenza $A\left(\mathrm{H}_{1} \mathrm{~N}_{1}\right)$ pdmog vaccines in 2009 [5]. Accordingly, the Swedish government had already in 2007 closed a contract with a pharmaceutical company for the purchase of an adjuvanted vaccine for the entire population in the case of an influenza pandemic [6].

Several studies have been carried out worldwide to investigate the effectiveness of pandemic influenza vaccines during the first pandemic season 2009/10 [7-22]. Studies of ASo3-adjuvanted, monovalent vaccines showed high effectiveness against influenza hospitalisation [17] and laboratory-confirmed influenza attended in primary care [18-21]. In Sweden, the weekly vaccine effectiveness against notified, laboratory-confirmed pandemic influenza was estimated at $87-95 \%$ in the population of Stockholm (ca. 2 million people) [22]. 


\section{FIGURE 1}

Counties providing age-specific coverage for the

Pandemrix vaccine, Sweden, 2009

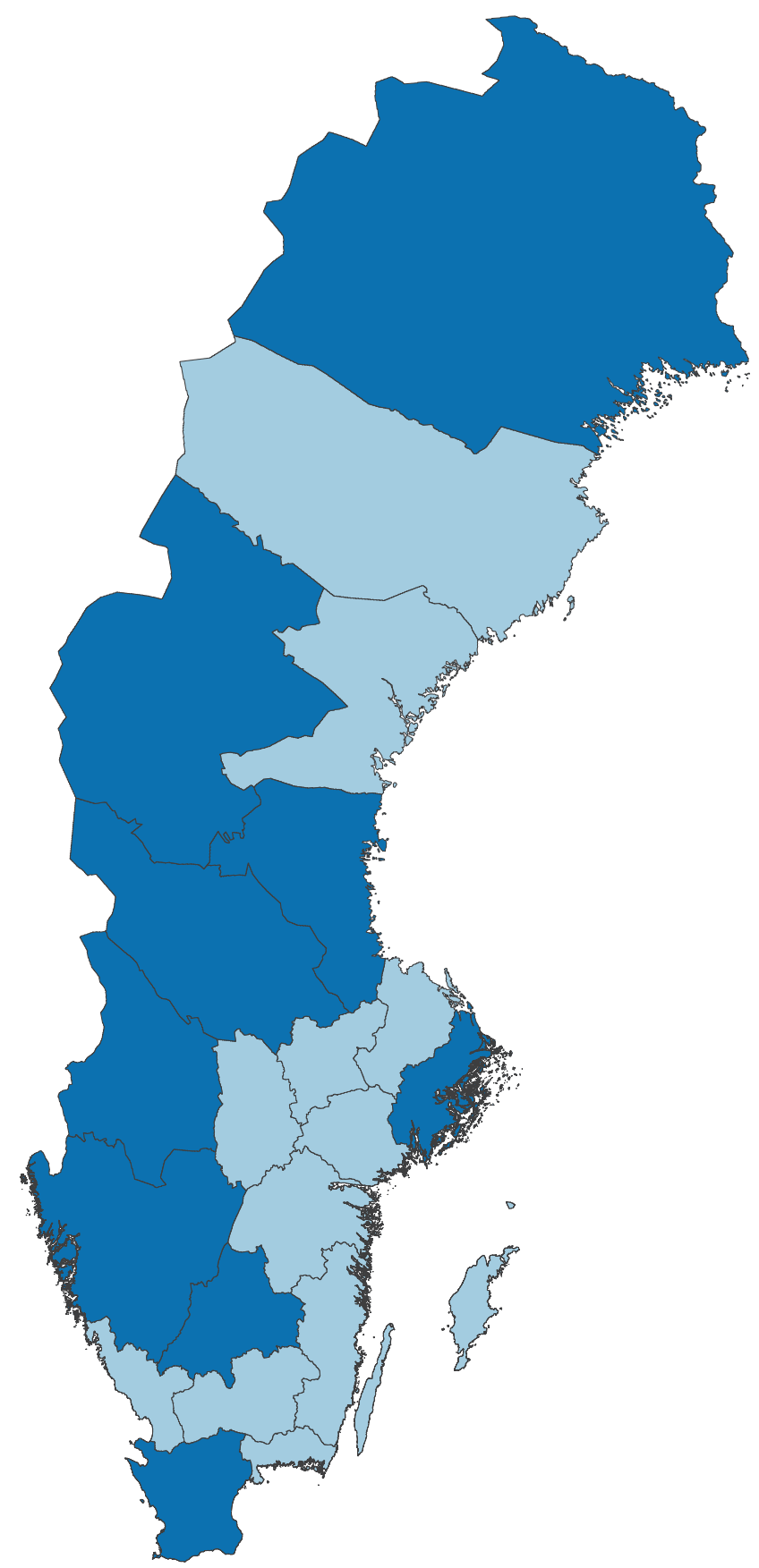

Dark blue: counties that provided coverage data.
In the subsequent influenza season, 2010/11, the pandemic virus strain was included in the trivalent seasonal vaccine, together with an influenza $A /$ Perth/16/2009 $\left(\mathrm{H}_{3} \mathrm{~N}_{2}\right)$ strain and an influenza B/Brisbane/60/2008 strain. The seasonal vaccination was offered free of charge or at reduced cost to people belonging to risk groups and people aged 65 years and older. During that season the pandemic strain was in circulation, mainly around the New Year [23]. The close match between the 2009 pandemic vaccine strain and the 2010/11 influenza $A\left(\mathrm{H}_{1} \mathrm{~N}_{1}\right)$ pdmog virus strain made it likely that the population could in the post-pandemic season still be protected by the pandemic vaccine administered more than one year earlier.

The pandemic mass vaccination in 2009 was a large and costly undertaking and therefore needed to be monitored and evaluated. However, at the time, a country-wide evaluation of the vaccine effectiveness was not planned, and data for it were not systematically collected in Sweden. Since evidence emerged on an association between the pandemic vaccination and the severe adverse event narcolepsy in children [24-29], an evaluation has become even more important. Studies on the effectiveness and the duration of protection induced by the pandemic vaccine are needed for an overall assessment of the vaccination and its risks and benefits. For this study, we used the best available data and methods to assess quickly the prevailing vaccine effectiveness against hospitalisation with laboratory-confirmed influenza $\mathrm{A}\left(\mathrm{H}_{1} \mathrm{~N}_{1}\right)$ pdmog one year after the pandemic vaccination campaign.

\section{Methods}

In Sweden, communicable disease control at the county level is coordinated by the 21 County Medical Officers (CMO). Currently, vaccination coverage data is also collected and administered by the CMOs. Different techniques for registering pandemic vaccination data were used in 2009, including: local vaccination registers, data extraction from medical charts, and a web-based vaccination register implemented in some counties (Svevac). Nine of 21 CMOs were able to provide the age-specific number of pandemic vaccinations (dose 1) administered during the autumn 2009. These nine counties comprise $68 \%$ of the Swedish population, they are scattered geographically (Figure 1) and cover the three major urban areas as well as the more scarcely populated areas in the north.

The organisation of the healthcare system does not differ much between the Swedish counties. The overall vaccination coverage in all counties versus those counties where age-specific vaccination coverage was available had overlapping ranges (54-70\% versus $54-69 \%$ ). We assumed that the vaccination coverage in counties with unknown age-specific coverage followed a normal distribution with the same, but unknown, mean as in the counties with known coverage. The total vaccination coverage in 2009, PPV, was estimated as follows: 


$$
P \hat{P} V=\sum_{i \in \mathcal{S}} w_{i} p_{i}+\hat{\mu} \sum_{i \notin \mathcal{S}} w_{i}
$$

where $\mathbf{w}_{\mathbf{i}}$ and $\mathbf{p}_{\mathbf{i}}$ are the proportion of the Swedish population and vaccination coverage in county $\boldsymbol{I}$, respectively, $\boldsymbol{S}$ is the sample of counties with known vaccination coverage, and $\hat{\boldsymbol{\mu}}$ is the estimate of the mean vaccination coverage, based on the counties with known coverage in $S$.

To calculate age-specific vaccination coverage we used population data as of December 2009 (Statistics Sweden).

Pandemic influenza was made notifiable with full patient identification in Sweden at the start of the 2009 pandemic and has since remained so. Laboratories are obliged by law to report all laboratory-confirmed cases to the CMO and the Swedish Institute for Communicable Disease Control (Smittskyddsinstitutet; SMI). The diagnostic method used is an in-house $\mathrm{H}_{1} \mathrm{~N}_{1}$-specific realtime PCR. Sensitivity and specificity were assessed by quality control panels from SMI. Doctors who admit a patient to hospital for suspected pandemic influenza are also obliged by law to report the case. Clinical signs and symptoms are not specified in the national case definition, which is based on laboratory confirmation, as is the case for all notifiable diseases in Sweden. Swabbing of suspected cases is in principle mandatory, since pandemic influenza is a notifiable disease. Any delay between onset of symptoms and swabbing is accepted. Laboratory notifications of confirmed cases are matched in SmiNet (the national database for notifications) to notification forms of hospitalised cases. For hospitalised cases, the notification form contains voluntary questions on vaccination and risk group status. Risk groups are defined as people with chronic respiratory disease, cardiovascular disease, obesity of class III (body mass index $>40 \mathrm{~kg} / \mathrm{m}^{2}$ ), neurological disorders with impaired breathing capacity, immunosuppression, chronic liver or kidney failure, severe diabetes, severe asthma and pregnancy as well as cerebral palsy or other neuromuscular disorders in children. All clinical notification forms were examined and updated by the CMOs at the end of the 2010/11 influenza season.

In this study, we included cases who had a laboratoryconfirmed influenza $A\left(\mathrm{H}_{1} \mathrm{~N}_{1}\right)$ pdmog infection and who

\section{TABLE 1}

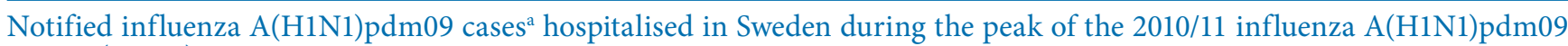
season $(n=252)$

\begin{tabular}{|c|c|c|c|}
\hline & $\begin{array}{l}\text { Cases with known vaccination status } \\
\qquad(\mathrm{n}=215)\end{array}$ & $\begin{array}{l}\text { Cases with unknown vaccination status } \\
\qquad(\mathrm{n}=37)\end{array}$ & $\mathrm{p}$ value \\
\hline & Median & Median & \\
\hline \multirow[t]{2}{*}{ Age (years) } & 35 & 44 & $0.062^{b}$ \\
\hline & $\mathrm{n}(\%)$ & n (\%) & \\
\hline \multicolumn{4}{|l|}{ Age group } \\
\hline 6 months -9 years & $26(12)$ & $3(8)$ & $0.617^{c}$ \\
\hline $10-19$ years & $18(8)$ & $2(5)$ & \\
\hline $20-39$ years & $82(38)$ & $12(32)$ & \\
\hline $40-64$ years & $89(41)$ & $20(54)$ & \\
\hline \multicolumn{4}{|l|}{ Sex } \\
\hline Female & $111(52)$ & $15(41)$ & $0.213^{d}$ \\
\hline Male & $104(48)$ & $22(59)$ & \\
\hline \multicolumn{4}{|l|}{ Risk group } \\
\hline Yes & $92(43)$ & $9(24)$ & $0.160 \mathrm{~d}^{\mathrm{e}}$ \\
\hline No & $107(50)$ & $19(51)$ & $0.003 \mathrm{~d}^{\mathrm{f}}$ \\
\hline Unknown & $16(7)$ & $9(24)$ & \\
\hline \multicolumn{4}{|l|}{ Pandemic vaccination } \\
\hline Yes & $63(29)$ & Missing data & Not applicable \\
\hline No & $152(71)$ & Missing data & Not applicable \\
\hline
\end{tabular}

a Restricted to cases aged six months to 64 years at the time of the 2009 pandemic influenza vaccination.

b Wilcoxon rank-sum test.

Fischer's exact test.

Chi-square test.

Excluding cases with unknown risk group status.

Including all cases. 
were admitted to hospital according to a notification form from a hospital doctor or according to the CMO. We only included cases who were hospitalised during the peak of the influenza $A\left(\mathrm{H}_{1} \mathrm{~N}_{1}\right)$ pdmog season 2010/11, defined as the time period with at least 50 notified cases per week nationally, i.e. between week $52 / 2010$ and week 7/2011. Cases with unknown pandemic vaccination status were excluded from the main analysis. The excluded cases were compared to cases with known vaccination status with regard to potential confounding factors, such as age, sex and risk group status, using appropriate statistical tests (Table 1).

Vaccine effectiveness (VE) was assessed using the screening method, where data on vaccination coverage among cases (proportion of cases vaccinated, PCV) and in the population (proportion of population vaccinated, $P P V)$ were inserted in the formula $V E=((P P V-P C V) /$ $(P P V(1-P C V)){ }^{\star} 100$ [30]. We used the method described by Farrington to obtain confidence intervals (CI) [31] and used the point estimate of PPV for the calculations.

For both PCV and PPV estimates, age at the time of the 2009 pandemic vaccination was used, i.e. more than a year before the outcome. Overall age-adjusted vaccine effectiveness was estimated as well as age-specific vaccine effectiveness for the following age groups: six months to nine years, 10 to 19 years, 20 to 39 years and 40 to 64 years. Children younger than six months at the time of the vaccination campaign were not eligible for the vaccination. Those aged 65 years and older had high vaccination coverage of the 2010/11 seasonal vaccine, which could have interfered with the results. Thus, both groups were excluded from the analysis. There was not enough statistical power to stratify both by age group and county. We chose to stratify by age group as this is a biologically more plausible confounder. We also carried out an analysis restricted only to cases that did not belong to risk groups. Since we did not have data on vaccination coverage in risk groups in the population, the entire general population of the same age was used as control group for this analysis.

\section{Results}

Some 320 cases with influenza $\mathrm{A}\left(\mathrm{H}_{1} \mathrm{~N}_{1}\right)$ pdmog infection were hospitalised during the peak period (week $52 / 2010$ to week 7/2011). Thirty-eight cases were younger than six months in the autumn of 2009 and 30 cases were 65 years or older, and therefore excluded. Vaccination status regarding the pandemic vaccine was known for $215(85 \%)$ of the remaining 252 cases, and these were kept in the final analysis. A majority of cases were between 20 and 64 years-old (Table 1). There were no statistically significant differences with regard to age, sex or risk group status between the groups with and without known vaccination status (Table 1).

Vaccination coverage was estimated at $60 \%$ in the general population (aged six months to 64 years), with the
FIGURE 2

Age-specific coverage of pandemic influenza vaccination modelled on reports from nine $e^{\mathrm{a}}$ of 21 counties in Sweden, 2009

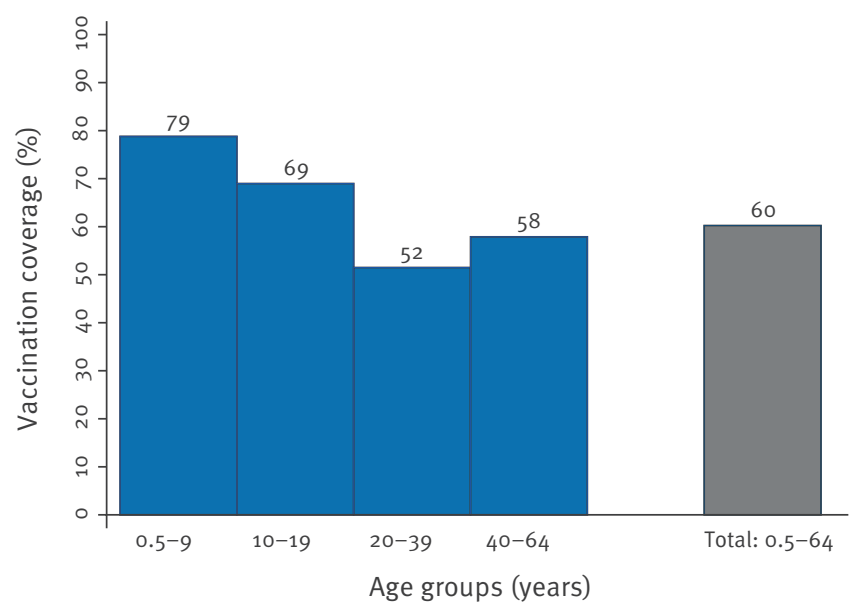

a The nine counties represent $68 \%$ of the population in Sweden.

highest coverage of $79 \%$ in children between the age of six months and nine years (Figure 2).

The overall age-adjusted (six months to 64 years) vaccine effectiveness was $72 \%$ (95\% Cl: $63-80 \%)$, and highest in the youngest age group six months to nine years, with $92 \%$ (95\% Cl: 80-97\%) (Table 2).

At least $43 \%$ of hospitalised influenza cases belonged to a risk group (Table 1). When restricting the analysis only to cases not belonging to a risk group, the vaccine effectiveness estimate increased to $82 \%(95 \% \mathrm{Cl}$ : 72-89\%).

\section{TABLE 2}

Age-specific effectiveness for the pandemic influenza vaccine administered during the autumn of 2009 against hospitalisation with influenza $\mathrm{A}(\mathrm{H} 1 \mathrm{~N} 1) \mathrm{pdm} 09$ infection during the peak of the influenza $\mathrm{A}(\mathrm{H} 1 \mathrm{~N} 1)$ pdm09 season in 2010/11 in Sweden

\begin{tabular}{|l|c|}
\hline Age group & $\begin{array}{c}\text { Vaccine effectiveness \% } \\
(95 \% \mathrm{Cl})\end{array}$ \\
\hline 6 months-9 years & $92 \%(80-97 \%)$ \\
\hline $10-19$ years & $78 \%(40-92 \%)$ \\
\hline $20-39$ years & $68 \%(47-80 \%)$ \\
\hline $40-64$ years & $63 \%(43-76 \%)$ \\
\hline Total $(6$ months-64 years) & $\mathbf{7 2} \%(63-80 \%)$ \\
\hline
\end{tabular}

$\mathrm{Cl}$ : confidence interval. 


\section{Discussion}

We applied the screening method to available surveillance data to assess the impact in the post-pandemic season 2010/11 of the adjuvanted pandemic influenza vaccine administered more than one year previously. Our results suggest a high prevailing vaccine effectiveness against hospitalisation with laboratory-confirmed influenza $A\left(\mathrm{H}_{1} \mathrm{~N}_{1}\right)$ pdmog among the Swedish population aged between six months and 64 years, with the highest protection in the young children. If verified by other studies, this could have important public health implications. Trivalent inactivated vaccines against seasonal influenza have not successfully induced protective immunity in children naïve to the virus [32-34]. Adjuvanted vaccines induce higher levels of haemagglutination inhibition ( $\mathrm{HI}$ ) and neutralising antibodies against influenza virus in naïve children [35-37] and in adults [38] than the non-adjuvanted trivalent vaccines. High antibody persistence one year after vaccination was demonstrated in children who had received two doses of the ASo3-adjuvanted vaccine in the United Kingdom, with a significant difference compared with children who had received a non-adjuvanted vaccine [39]. In a study of children in Canada, persistent antibody titres were found after one dose of an ASo3adjuvanted influenza vaccine [40]. In addition, Swedish serological data confirmed that more than $80 \%$ of $5^{-14}$ year-old Swedish children had sustained elevated HI-antibody titres of $\geq 40$ in May 2011, 18 months after the pandemic vaccination campaign [41]. Although antibody titres are an unspecific marker for influenza immunity, these results are in line with our findings of persistent protection. Such lasting protection and the ability to induce priming in children are extremely beneficial in a pandemic situation.

However, the association between the pandemic influenza vaccine and narcolepsy seen in children in Finland, Ireland, Norway and Sweden [24-29] has raised serious concerns about the safety of Pandemrix. The European Medicines Agency recommends a restricted use of the vaccine in persons younger than 20 years [42]. An association with such a severe adverse event makes recommendations to use Pandemrix and similarly adjuvanted vaccines very difficult to adopt and implement, probably even in the context of a new pandemic. Thus, the association between the vaccine and narcolepsy needs to be thoroughly understood in order to make decisions on the future use of similar vaccines. Many studies on the link between narcolepsy and the pandemic vaccine are ongoing and will hopefully provide guidance on this issue.

Before the pandemic, very few studies had looked at the lasting protection of influenza vaccination. However, several studies have now investigated the prevailing vaccine effectiveness of pandemic influenza vaccines in the 2010/11 season [43-48]. Firstly, some of these studies have found that the vaccine effectiveness was higher for people who had received both the pandemic vaccine and the seasonal 2010/11 trivalent influenza vaccine than for those who had received only one $[44,45]$. Secondly, compared with our estimates, some have found lower prevailing vaccine effectiveness after receipt of only the pandemic vaccine [4346]. However, the results from these studies cannot be easily compared with ours for one or several reasons. (i) They used another outcome: primary care-attended laboratory-confirmed influenza instead of severe influenza; (ii) they used other pandemic vaccines or a mix of vaccines; (iii) they included different age groups and/or restricted the analysis to risk groups or people with comorbidities. Moreover, these studies used more elaborate study designs such as the test-negative case-control design or cohort design. By using the screening method, our study is more prone to bias and confounding, and differences could be explained by positive confounding in our study.

Nonetheless, our findings of a high prevailing effectiveness of the pandemic vaccine, particularly in the young, are supported by results from Canada, where a similar vaccine was used. In a test-negative casecontrol study the prevailing effectiveness of an ASo3adjuvanted monovalent pandemic vaccine was $66 \%$ in all patients and $76 \%$ among young adults [47]. In addition, the high degree of protection from vaccination in Sweden may have reduced the virus burden in the population, resulting in lower infectious doses with a more limited possibility of overcoming the vaccine-induced protection.

Our aim was to achieve an assessment of prevailing vaccine effectiveness easily and quickly, but it proved to be a cumbersome process, due to the lack of vaccination registers. This underlines the importance of concurrent planning of the implementation and the evaluation of large public health actions. We used the best available data and method. However, both have inherent limitations and the results need to be interpreted with caution. We tried to address the potential limitations one by one. To increase the quality of the influenza surveillance data in the country, the CMOs were asked to cross-check and validate vaccination and hospitalisation status for each notified case at the end of the season. The completeness of the data was more difficult to improve or assess. All laboratoryconfirmed cases are subject to mandatory reporting, which is mainly an automated process. Swabbing of suspected cases is in principle also mandatory as pandemic influenza is a notifiable disease, but we could not assess the extent to which this was done and thus how complete the reporting was. As expected, when working with surveillance data we faced issues with missing data. Because we aimed at a quick and easy estimate of prevailing vaccine effectiveness, we chose to exclude cases without data on vaccination status rather than using imputation techniques. There were no apparent differences between cases with and without data on vaccination status in the descriptive analysis (Table 1). Nonetheless, there could have been differences in these groups that we have failed to adjust for. 
Vaccine effectiveness studies can be affected both by 'confounding by indication' and by confounding due to 'healthy vaccinee' effect, leading to an underestimation and an overestimation of results, respectively [49]. Also, the screening method may overestimate the vaccine effectiveness when the coverage is high [30]. Generally, the main confounder in vaccine effectiveness studies is age; to address this we stratified and adjusted our analysis by age group. Furthermore, since we used surveillance data, we were not able to adjust for receipt of the trivalent $2010 / 11$ seasonal influenza vaccine, which was a major confounder in other studies $[44,45]$. In order to address this limitation, we restricted our analysis to an age group where seasonal vaccination is generally not recommended except for risk groups. Only $7 \%$ (10 of 141 cases with known seasonal vaccination status; data not shown) of hospitalised cases had had the seasonal vaccination, and according to vaccination coverage surveys carried out by SMI and others [50], this is in line with the seasonal vaccination coverage in this age group in previous years. Hence, this factor should not play a major role as a confounder in our analysis. On the other hand, the impact of natural immunity due to infection during the pandemic season is difficult to predict. Mass vaccination was carried out concurrently with the peak of the pandemic. Refusal, delay or even request of vaccination due to ongoing or previous influenza symptoms as well as boosting of vaccine response due to subclinical infection is plausible. Again, both an overestimation and an underestimation of the results are possible.

Yet another factor to take into account is risk group status. Nearly half of the hospitalised cases included in the study belonged to a risk group. There is no national data on exact risk group prevalence in the general population, although, according to surveys carried out by SMI between $4 \%$ and $14 \%$ of people in the relevant age groups consider themselves to belong to a risk group for influenza vaccination. It is fair to say that people belonging to risk groups are overrepresented among our cases. These groups were targeted and prioritised for pandemic vaccination and higher vaccination coverage among them is anticipated, making risk group status a likely confounder in our study. Since we could not adjust for this factor, we carried out a sensitivity analysis; vaccine effectiveness slightly increased when we restricted the analysis to cases that did not belong to risk groups, an indication that failing to adjust for risk factor status have at least not lead to an overestimation of results in our main analysis.

Sweden had 1.1 influenza-related deaths per $10^{6}$ population during the winter 2010/11 [23], a rate dramatically lower than described in countries with lower pandemic vaccination coverage $[51,52]$, and the impact on intensive care units was substantially lower in Sweden than elsewhere [51-53]. In fact, some countries have described a higher burden of severe disease in the post-pandemic season than during the pandemic season [51,54], which was not the case for Sweden [23]. Notwithstanding the limitations above, we believe our estimates reflect a high, prevailing influenza vaccine effectiveness of the adjuvanted vaccine administered in 2009, protecting a large part of the Swedish population against hospitalisation with influenza $A\left(\mathrm{H}_{1} \mathrm{~N}_{1}\right)$ pdmog infection also during the $2010 / 11$ season.

Acknowledgements

We would like to thank reporting doctors. We would also like to thank Marta Valenciano at EpiConcept, Baltazar Nunes at the Instituto Nacional de Saúde Dr Ricardo Jorge and the I-MOVE network as well as AnnaSara Carnahan at the Swedish Institute for Communicable Disease Control. 


\section{References}

1. European Centre for Disease Prevention and Control (ECDC). Seasonal Influenza 2010-2011 in Europe (EU/EEA countries). Stockholm: ECDC; 2011. Available from: http://ecdc.europa.eu/ en/publications/publications/110125_ra_seasonal_influenza_ eu-eea_2010-2011.pdf

2. Walker WT, Faust SN. Monovalent inactivated split-virion ASo3-adjuvanted pandemic influenza $A\left(\mathrm{H}_{1} \mathrm{~N}_{1}\right)$ vaccine. Expert Rev Vaccines. 2010;9(12):1385-98. http://dx.doi.org/10.1586/ erv.10.141. PMid:21105775.

3. Nichol KL, Treanor JJ. Vaccines for seasonal and pandemic influenza. J Infect Dis. 2006;194 Suppl 2:S111-8. http://dx.doi. org/10.1086/507544. PMid:17163383.

4. World Health Organization (WHO). Influenza pandemic preparedness and response, Report by the secretariat. Geneva: WHO; 2005. Contract No.: EB115/44. Available from: http:// www.wpro.who.int/emerging_diseases/documents/docs/ B115_44en.pdf

5. Pandemic influenza $A\left(\mathrm{H}_{1} \mathrm{~N}_{1}\right) 2009$ virus vaccine - conclusions and recommendations from the October 2009 meeting of the immunization Strategic Advisory Group of Experts. Wkly Epidemiol Rec. 2009;84(49):505-8. PMid:19960623.

6. Influensa $A\left(\mathrm{H}_{1} \mathrm{~N}_{1}\right) 2009$ - Utvärdering och förberedelser för hantering av pandemin. [Influenza $A\left(\mathrm{H}_{1} \mathrm{~N}_{1}\right) 2009$ - Evaluation and preparation for managament of the pandemic]. Stockholm: Socialstyrelsen, Karlstad: Myndigheten för samhällsskydd och beredskap; 2011. ISBN: 978-91-86585-84-6. Swedish. Available from: http://www.socialstyrelsen.se/Lists/Artikelkatalog/ Attachments/18243/2011-3-3.pdf

7. Cheng AC, Kotsimbos T, Kelly HA, Irving LB, Bowler SD, Brown SG, et al. Effectiveness of $\mathrm{H}_{1} \mathrm{~N}_{1} / 09$ monovalent and trivalent influenza vaccines against hospitalization with laboratoryconfirmed $\mathrm{H}_{1} \mathrm{~N}_{1} / 09$ influenza in Australia: A test-negative case control study. Vaccine. 2011;29(43):7320-5. http://dx.doi. org/10.1016/j.vaccine.2011.07.087. PMid:21810450.

8. Valenciano M, Kissling E, Cohen JM, Oroszi B, Barret AS, Rizzo $C$, et al. Estimates of pandemic influenza vaccine effectiveness in Europe, 2009-2010: results of Influenza Monitoring Vaccine Effectiveness in Europe (I-MOVE) multicentre case-control study. PLoS Med. 2011;8(1):e1000388. http:// dx.doi.org/10.1371/journal.pmed.1000388. PMid:21379316. PMCid:3019108.

9. Hardelid P, Fleming DM, McMenamin J, Andrews N, Robertson C, SebastianPillai P, et al. Effectiveness of pandemic and seasonal influenza vaccine in preventing pandemic influenza $\mathrm{A}\left(\mathrm{H}_{1} \mathrm{~N}_{1}\right)_{2009}$ infection in England and Scotland 2009-2010. Euro Surveill. 2011;16(2):pii=19763. Available from: http:// www.eurosurveillance.org/ViewArticle.aspx?Articleld $=19763$

10. Griffin MR, Monto AS, Belongia EA, Treanor J], Chen Q, Chen J, et al. Effectiveness of Non-Adjuvanted Pandemic Influenza A Vaccines for Preventing Pandemic Influenza Acute Respiratory Illness Visits in 4 U.S. Communities. PloS One. 2011;6(8):e23085. http://dx.doi.org/10.1371/journal. pone.0023085. PMid:21857999. PMCid:3155536.

11. Pelat C, Falchi A, Carrat F, Mosnier A, Bonmarin I, Turbelin C, et al. Field effectiveness of pandemic and 2009-2010 seasonal vaccines against 2009-2010 $A\left(\mathrm{H}_{1} \mathrm{~N}_{1}\right)$ influenza: estimations from surveillance data in France. PloS One. 2011;6(5):e19621. http://dx.doi.org/10.1371/journal.pone.0019621. PMid:21573005. PMCid:3091864.

12. Steens A, Wijnans EG, Dieleman JP, Sturkenboom MC, van der Sande MA, van der Hoek W. Effectiveness of a MF-59adjuvanted pandemic influenza vaccine to prevent $2009 \mathrm{~A} /$ $\mathrm{H}_{1} \mathrm{~N}_{1}$ influenza-related hospitalisation; a matched casecontrol study. BMC Infect Dis. 2011;11:196. http://dx.doi. org/10.1186/1471-2334-11-196. PMid:21767348. PMCid:3154871.

13. Steens A, van der Hoek W, Dijkstra F, van der Sande M. Influenza vaccine effectiveness, 2010/11. Euro Surveill. 2011;16(15):pii=19843. Available from: http://www. eurosurveillance.org/ViewArticle.aspx?Articleld=19843. PMid:21507318.

14. Hardelid P, Fleming DM, Andrews N, Barley M, Durnall $\mathrm{H}$, Mangtani $\mathrm{P}$, et al. Effectiveness of trivalent and pandemic influenza vaccines in England and Wales 20082010: results from a cohort study in general practice. Vaccine. 2012;30(7):1371-8. http://dx.doi.org/10.1016/j. vaccine.2011.12.038. PMid:22178524.

15. Fielding JE, Grant KA, Garcia K, Kelly HA. Effectiveness of seasonal influenza vaccine against pandemic $\left(\mathrm{H}_{1} \mathrm{~N}_{1}\right) 2009$ virus, Australia, 2010. Emerg Infect Dis. 2011;17(7):1181-7. http://dx.doi.org/10.3201/eid1707.101959. PMid:21762570. PMCid:3381383.

16. Puig-Barbera J, Arnedo-Pena A, Pardo-Serrano F, TiradoBalaguer MD, Perez-Vilar S, Silvestre-Silvestre E, et al. Effectiveness of seasonal 2008-2009, 2009-2010 and pandemic vaccines, to prevent influenza hospitalizations during the autumn 2009 influenza pandemic wave in Castellon, Spain. A test-negative, hospital-based, case-control study. Vaccine. 2010;28(47):7460-7. http://dx.doi.org/10.1016/j. vaccine.2010.09.042. PMid:20875486.

17. Gilca R, Deceuninck G, De Serres G, Boulianne N, Sauvageau C, Quach C, et al. Effectiveness of Pandemic $\mathrm{H}_{1} \mathrm{~N}_{1}$ Vaccine Against Influenza-Related Hospitalization in Children. Pediatrics. 2011;128(5):e1084-91. http://dx.doi.org/10.1542/peds.20103492. PMid:21987710.

18. Skowronski DM, Janjua NZ, De Serres G, Hottes TS, Dickinson JA, Crowcroft N, et al. Effectiveness of ASoz adjuvanted pandemic $\mathrm{H}_{1} \mathrm{~N}_{1}$ vaccine: case-control evaluation based on sentinel surveillance system in Canada, autumn 2009. BMJ. 2011;342:C7297. http://dx.doi.org/10.1136/bmj.c7297. PMid:21292718. PMCid:3033439.

19. Wichmann O, Stocker P, Poggensee G, Altmann D, Walter $D$, Hellenbrand W, et al. Pandemic influenza $A\left(\mathrm{H}_{1} \mathrm{~N}_{1}\right) 2009$ breakthrough infections and estimates of vaccine effectiveness in Germany 2009-2010. Euro Surveill. 2010;15(18):pii=19561. Available from: http://www.eurosurveillance.org/ViewArticle. aspx?Articleld=19561. PMid:20460094.

20. Emborg HD, Krause TG, Hviid A, Simonsen J, Mølbak K. Effectiveness of vaccine against pandemic influenza $A / \mathrm{H}_{1} \mathrm{~N}_{1}$ among people with underlying chronic diseases: cohort study, Denmark, 2009-10. BMJ. 2011;344:d7901. http://dx.doi. org/10.1136/bmj.d7901. PMid:22277542.

21. Andrews N, Waight P, Yung CF, Miller E. Age-specific effectiveness of an oil-in-water adjuvanted pandemic $\left(\mathrm{H}_{1} \mathrm{~N}_{1}\right)$ 2009 vaccine against confirmed infection in high risk groups in England. J Infect Dis. 2011;203(1):32-9. http://dx.doi. org/10.1093/infdis/jiq014. PMid:21148494. PMCid:3086445.

22. Örtqvist A, Berggren I, Insulander M, de Jong B, Svenungsson $B$. Effectiveness of an adjuvanted monovalent vaccine against the 2009 pandemic strain of influenza $A\left(\mathrm{H}_{1} \mathrm{~N}_{1}\right) \mathrm{v}$, in Stockholm County, Sweden. Clin Infect Dis. 2011;52(10):1203-11. http:// dx.doi.org/10.1093/cid/cir182. PMid:21507917.

23. Smittskyddsinstitutet (SMI). Influensa i Sverige, säsongen 2010-2011. [Influenza in Sweden, the 2010-2011 season]. Stockholm: SMI; 2011. Swedish. Available from: http://www. smittskyddsinstitutet.se/upload/Publikationer/Influensa-iSverige-2010-11-artikelnr-2011-15-2.pdf

24. Läkemedelsverket. Occurrence of narcolepsy with cataplexy among children and adolescents in relation to the $\mathrm{H}_{1} \mathrm{~N}_{1}$ pandemic and Pandemrix vaccinations $\square$ Results of a case inventory study by the MPA in Sweden during 2009-2010. Stockholm: Läkemedelsverket; 2011. Available from: http://www.lakemedelsverket.se/upload/nyheter/2011/ Fallinventeringsrapport_pandermrix_110630.pdf

25. National Narcolepsy Task Force Interrim Report. Helsinki: National Institute for Health and Welfare; 2011. Available from: http://www.thl.fi/thl-client/pdfs/ dce182fb-651e-48a1-b018-3f774d6d1875

26. Nohynek H, Jokinen J, Partinen M, Vaarala O, Kirjavainen T, Sundman J, et al. ASo3 Adjuvanted $\mathrm{AH}_{1} \mathrm{~N}_{1}$ Vaccine Associated with an Abrupt Increase in the Incidence of Childhood Narcolepsy in Finland. PloS One. 2012;7(3):e33536. http:// dx.doi.org/10.1371/journal.pone.0033536. PMid:22470453. PMCid:3314666.

27. Partinen M, Saarenpaa-Heikkila O, Ilveskoski I, Hublin C, Linna $M$, Olsen $P$, et al. Increased Incidence and Clinical Picture of Childhood Narcolepsy following the $2009 \mathrm{H}_{1} \mathrm{~N}_{1}$ Pandemic Vaccination Campaign in Finland. PloS One. 2012;7(3):e33723. http://dx.doi.org/10.1371/journal.pone.0033723. PMid:22470463. PMCid:3314680.

28. Investigation of an increase in the incidence of narcolepsy in children and adolescents in 2009 and 2010 - Final Report of National Narcolepsy Study Steering Committee. Dublin: Irish Department of Health; 2012. Available from: http:// healthupdate.gov.ie/wp-content/uploads/2012/04/Final Report_of_National_Narcolepsy_Study_Steering_Committee-

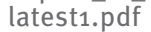

29. Folkehelseinstituttet (FHI). Rapport om utredning av narkolepsi etter Pandemrix [Report from the investigation of narcolepsy after Pandemrix]. Oslo: FHI; 2011. Norwegian. Available from: http://www.fhi.no/dav/842b470e7d.pdf

30. Orenstein WA, Bernier RH, Dondero TJ, Hinman AR, Marks JS, Bart KJ, et al. Field evaluation of vaccine efficacy. Bull World Health Organ. 1985;63(6):1055-68. PMid:3879673. PMCid:2536484.

31. Farrington CP. Estimation of vaccine effectiveness using the screening method. Int J Epidemiol. 1993;22(4):742-6. http:// dx.doi.org/10.1093/ije/22.4.742. PMid:8225751.

32. Jefferson T, Rivetti A, Harnden A, Di Pietrantonj C, Demicheli V. Vaccines for preventing influenza in healthy children. Cochrane Database Syst Rev. 2008(2):CDo04879. PMid:18425905. 
33. Prevention and control of influenza with vaccines: recommendations of the Advisory Committee on Immunization Practices (ACIP), 2011. MMWR Morb Mortal Wkly Rep. 2011;60(33):1128-32. PMid:21866086.

34. Granström M, Voordouw AC. Registration of influenza vaccines for children in Europe. Vaccine. 2011;29(43):7572-5. http:// dx.doi.org/10.1016/j.vaccine.2011.08.017. PMid:21820474.

35. Waddington CS, Walker WT, Oeser C, Reiner A, John T, Wilkins $\mathrm{S}$, et al. Safety and immunogenicity of ASo3B adjuvanted split virion versus non-adjuvanted whole virion $\mathrm{H}_{1} \mathrm{~N}_{1}$ influenza vaccine in UK children aged 6 months-12 years: open label, randomised, parallel group, multicentre study. BMJ. 2010;340:c2649. http://dx.doi.org/10.1136/bmj.c2649. PMid:20508026. PMCid:2877808.

36. Vesikari T, Knuf M, Wutzler P, Karvonen A, Kieninger-Baum D, Schmitt HJ, et al. Oil-in-water emulsion adjuvant with influenza vaccine in young children. N Engl J Med. 2011;365(15):1406-16. http://dx.doi.org/10.1056/NEJMoa1010331. PMid:21995388.

37. Vesikari T, Pellegrini M, Karvonen A, Groth N, Borkowski A, O'Hagan DT, et al. Enhanced immunogenicity of seasonal influenza vaccines in young children using MF59 adjuvant. Pediatr Infect Dis J. 2009;28(7):563-71. http://dx.doi. org/10.1097/INF.ob013e31819d6394. PMid:19561422.

38. Ferguson M, Risi G, Davis M, Sheldon $E$, Baron $M$, Li P, et al. Safety and long-term humoral immune response in adults after vaccination with an $\mathrm{H}_{1} \mathrm{~N}_{1} 2009$ pandemic influenza vaccine with or without ASo3 adjuvant. J Infect Dis. 2012;205(5):73344. http://dx.doi.org/10.1093/infdis/jir641. PMid:22315336.

39. Walker WT, de Whalley P, Andrews N, Oeser C, Casey M, Michaelis L, et al. $\mathrm{H}_{1} \mathrm{~N}_{1}$ Antibody Persistence 1 Year After Immunization With an Adjuvanted or Whole-Virion Pandemic Vaccine and Immunogenicity and Reactogenicity of Subsequent Seasonal Influenza Vaccine: A Multicenter Follow-on Study. Clin Infect Dis. 2012;54(5):661-9. http://dx.doi.org/10.1093/ cid/cir905. PMid:22267719. PMCid:3275760.

40. Gilca V, De Serres G, Hamelin ME, Boivin G, Ouakki M, Boulianne N, et al. Antibody persistence and response to 2010-2011 trivalent influenza vaccine one year after a single dose of 2009 ASo3-adjuvanted pandemic $\mathrm{H}_{1} \mathrm{~N}_{1}$ vaccine in children. Vaccine. 2011;30(1):35-41. http://dx.doi.org/10.1016/j. vaccine.2011.10.062. PMid:22063386

41. Mörner A, Bråve A, Kling AM, Kühlmann-Berenzon S, Krook K, Hedenskog M, et al. Pandemic Influenza A(H1 $\left.\mathrm{N}_{1}\right)$ pdmog Seroprevalence in Sweden before and after the Pandemic and the Vaccination Campaign in 2009. PloS One. 2012;7(12):e53511. http://dx.doi.org/10.1371/journal. pone.0053511. PMid:23285299 PMCid:3532299.

42. European Medicines Agency (EMA). European Medicines Agency recommends restricting use of Pandemrix. Press release. London: EMA; 2011. [Accessed 19 Apr 2012]. Available from: http://www.ema.europa.eu/ema/index.jsp?curl=pages/ medicines/human/public_health_alerts/2011/o7/human pha detail_000034.jsp\&mid=WCob01ac058001d126\&jsenabled=tr ue\#press-release

43. Kissling E, Valenciano M, Cohen JM, Oroszi B, Barret AS, Rizzo C, et al. I-MOVE multi-centre case control study 201011: overall and stratified estimates of influenza vaccine effectiveness in Europe. PloS One. 2011;6(11):e27622. http:// dx.doi.org/10.1371/journal.pone.0027622. PMid:22110695 PMCid:3216983.

44. Pebody RG, Andrews N, Fleming DM, McMenamin J, Cottrell S Smyth B, et al. Age-specific vaccine effectiveness of seasonal $2010 / 2011$ and pandemic influenza $A\left(H_{1} N_{1}\right) 2009$ vaccines in preventing influenza in the United Kingdom. Epidemiol Infect. 2012;13:1-11.

45. Castilla J, Moran J, Martinez-Artola V, Reina G, Martinez-Baz I, Garcia Cenoz M, et al. Effectiveness of trivalent seasonal and monovalent influenza $A\left(\mathrm{H}_{1} \mathrm{~N}_{1}\right) 2009$ vaccines in population with major chronic conditions of Navarre, Spain: 2010/11 mid-season analysis. Euro Surveill. 2011;16(7):pii=19799. Available from: http://www.eurosurveillance.org/ViewArticle. aspx?Articleld=19799. PMid:21345321.

46. Savulescu C, Jiménez-Jorge S, de Mateo S, Ledesma J, Pozo $\mathrm{F}$, Casas I, et al. Effectiveness of the $2010 / 11$ seasonal trivalent influenza vaccine in Spain: preliminary results of a case-control study. Euro Surveill. 2011;16(11):pii=19820. Available from: http://www.eurosurveillance.org/ViewArticle. aspx?Articleld=19820. PMid:21435330.

47. Skowronski DM, Janjua NZ, De Serres G, Winter AL, Dickinson JA, Gardy JL, et al. A sentinel platform to evaluate influenza vaccine effectiveness and new variant circulation, Canada 2010-2011 season. Clin Infect Dis. 2012;55(3):332-42. http:// dx.doi.org/10.1093/cid/cis431. PMid:22539661.

48. Jiménez-Jorge S, Savulescu C, Pozo F, de Mateo S, Casas I, Ledesma J, et al. Effectiveness of the 2010-11 seasonal trivalent influenza vaccine in Spain: cycEVA study. Vaccine.
2012;30(24):3595-602. http://dx.doi.org/10.1016/j. vaccine.2012.03.048. PMid:22472792.

49. Valenciano $M$, Ciancio $B$, Moren $A$, the influenza vaccine effectiveness working group. First steps in the design of a system to monitor vaccine effectiveness during seasonal and pandemic influenza in EU/EEA Member States. Euro Surveill. 2008;13(43):pii=19015. Available from: http://www. eurosurveillance.org/ViewArticle.aspx?Articleld=19015. PMid:18947520.

50. Kroneman MW, van Essen GA. Variations in influenza vaccination coverage among the high-risk population in Sweden in 2003/4 and 2004/5: a population survey. BMC Public Health. 2007;7:113. http://dx.doi.org/10.1186/14712458-7-113. PMid:17570837. PMCid:1906854.

51. Athanasiou M, Baka A, Andreopoulou A, Spala G, Karageorgou $\mathrm{K}$, Kostopoulos L, et al. Influenza surveillance during the post-pandemic influenza 2010/11 season in Greece, 04 October 2010 to 22 May 2011. Euro Surveill. 2011;16(44):pii=20004. Available from: http://www.eurosurveillance.org/ViewArticle. aspx?Articleld $=20004$

52. Health Protection Agency (HPA). Surveillance of influenza and other respiratory viruses in the UK, 2010/11. London: HPA; 2011. Available from: http://www.hpa.org.uk/Publications/ InfectiousDiseases/Influenza/1105influenzareport/

53. Glismann SO, Knudsen LK, Gubbels S, Mølbak K, Bragstad K, Nielsen LP. Influenza season 2010/2011. EpiNews. 2011;23. Available from: http://www.ssi.dk/English/News/EPINEWS/2011/No\%2023\%20-\%202011.aspx

54. Bolotin S, Pebody R, White PJ, McMenamin J, Perera L, NguyenVan-Tam JS, et al. A New Sentinel Surveillance System for Severe Influenza in England Shows a Shift in Age Distribution of Hospitalised Cases in the Post-Pandemic Period. PloS One. 2012;7(1):e30279. http://dx.doi.org/10.1371/journal. pone.0030279. PMid:22291929. PMCid:3264602 